\title{
Bleeding Control with Warm Saline Irrigation during Functional Endoscopic Sinus Surgery
}

\author{
Timmy Wibisono ${ }^{\text {a }}$, Budi Sutikno ${ }^{\mathrm{a}}$ \\ official email address : budi-s@fk.unair.ac.id

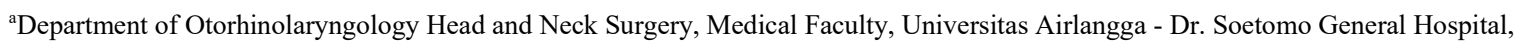 \\ Surabaya 60286, Indonesia
}

\begin{abstract}
Background: Functional endoscopic sinus surgery is a surgical technique that requires a clear surgical field in which bleeding occurs during surgery may become obstacle for surgeon. Warm saline irrigation produce hemostasis to control mucosal bleeding during surgery. Objective: To demonstrate the effectiveness of warm saline irrigation as mucosal bleeding control during FESS. Cases: There were four cases, two male and one female with chronic rhinosinusitis (CRS) with nasal polyps and one male with allergic fungal rhinosinusitis (AFRS) underwent a FESS. A warm saline irrigation was administered during all procedures, Boezaart score was used to assessed bleeding grade during surgery. Methods: Literature search found 86 journals from Pubmed and Springer database, and there were three articles met the criteria. Results: Three articles obtained were met the criteria in term of study providing warm saline irrigation at temperatures up to $50^{\circ} \mathrm{C}$ as a mucosal bleeding control during FESS able to be effective in more than two hours surgical time. Conclusion: Warm saline irrigation for FESS can reduce bleeding thereby affecting a better surgical field.
\end{abstract}

Keyword : warm saline irrigation; hemostasis; Functional Endoscopic Sinus Surgery (FESS)

\section{Introduction}

Endoscopic surgery is a minimally invasive surgical technique that has begun to be used in various operating fields. Endoscopic surgery can be a direct basic procedure such as functional endoscopic sinus surgery (FESS) and more advanced procedure such as endoscopic skull base surgery. ${ }^{1}$

Generally FESS is a safe procedure, but complications may occur in the form of intraoperative bleeding which may affect the duration and outcome of the operation. ${ }^{2}$ Intraoperative bleeding can be minimized by a good pre operative preparation, and intraoperatively. ${ }^{3}$ 
One method can be used to minimize intraoperative bleeding is warm saline irrigation. Warm saline irrigation is easy to perform and noninvasive technique to produce intraoperative hemostasis. Warm saline irrigation may cause vasodilatation and edema of the nasal mucosa, thereby reducing intraluminal blood flow by creating surrounding pressure. Mucosal blood pressure generates local pressure on injured blood vessels, and accelerating the blood clotting mechanism. Another advantage of warm saline irrigation is that it can keep the endoscopic lens clear. ${ }^{4,5}$

The aim of this evidence-based case report is to know the effectiveness of warm saline irrigation as mucosal bleeding control during FESS.

\section{Case Report}

There were three cases of CRS with nasal polyps, and one case of AFRS performed fullhouse FESS. All patients underwent the same surgical procedure, namely uncinectomy, middle meatal antrostomy, total ethmoidectomy, sphenoidectomy, frontal sinusotomy.

First case, a 72-year-old male presented a bilateral nasal obstruction since ten years ago. History of poor compliance medical treatment. Nasoendoscopy revealed multiple grade 3 polyp masses on the right nostril and grade 2 on the left nostril (Figure 1). Computed tomography scan (CT scan) of the paranasal sinuses, show a solid mass at right nostril (26HU), and also in the left nostril (37HU), extends to the nasopharynx, showing mucosal thickening of the frontal sinuses, left maxillary sinus, ethmoid sinuses, and sphenoid sinus (Figure 2).

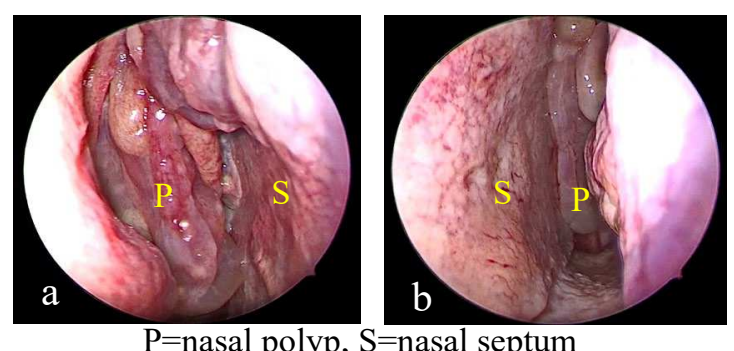

Figure 1. Nasoendoscopy revealed multiple grade 3 polyp masses on the right nostril (a) and grade 2 on the left nostril (b). 

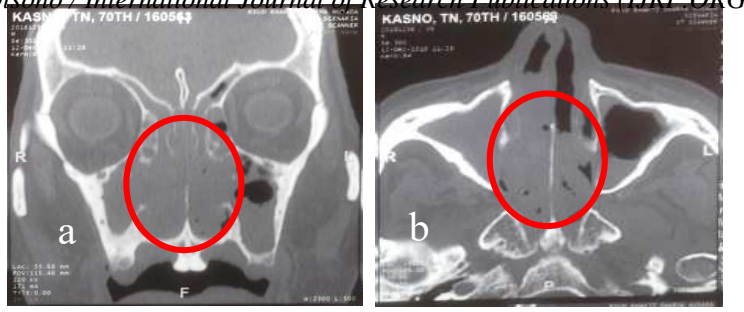

Figure 2. CT scan, solid mass in the right nostril, and solid mass in the left nostril extended to the nasopharynx

The surgery lasted for two hours without complications, blood loss was approximately $100 \mathrm{ml}$, Boezaart score 2 (Figure 3).

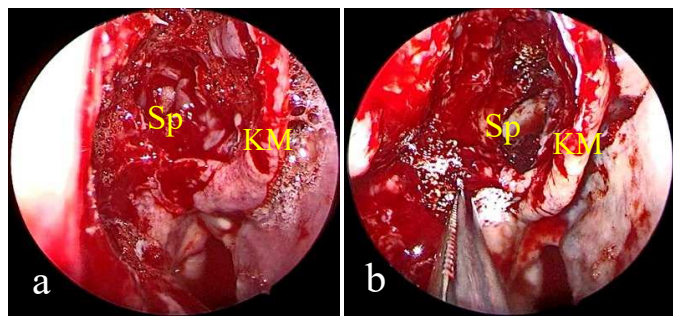

$\mathrm{Sp}=$ sphenoid sinus, $\mathrm{KM}=$ medial turbinate

Figure 3. (a) bleeding control using warm saline irrigation. (b) bleeding controlled, better surgical field of view.

Second case, a 67-year-old male presented a right nasal obstruction since one year ago, worsening in the last three months, nasal discharge on the right and left nostrils have recurred since three months ago, thick mucus, yellowish, loss of smell of the right nostril, a history of dust allergy, and smoking habits. History of poor compliance medical treatment. Nasoendoscopy revealed grade 3 polyp mass with smooth surface on the right nostril (Figure 4). CT scan of the paranasal sinuses showed a solid mass in the right nasal cavity, undefined margins, irregular edges with extension to the frontal sinus (Figure 5).

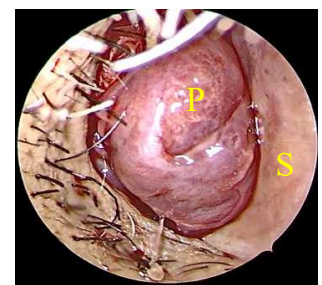

$\mathrm{P}=$ nasal polyp, $\mathrm{S}=$ nasal septum.

Figure 4. Nasoendoscopy revealed a nasal polyp at right nostril. 

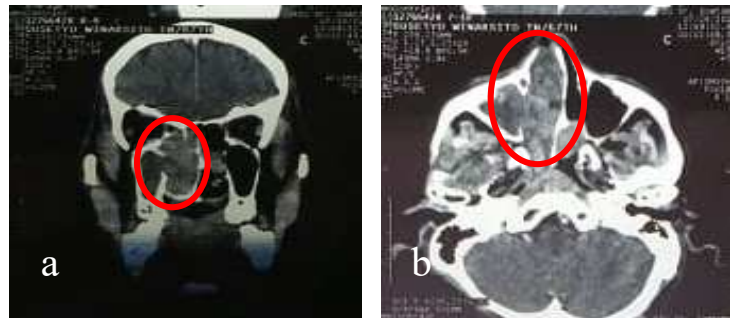

Figure 5. CT scan showed mass on right nostril expanded to choane

The surgery lasted for one and a half hour without complications, blood loss was approximately $75 \mathrm{ml}$, Boezaart score 2 (Figure 6).

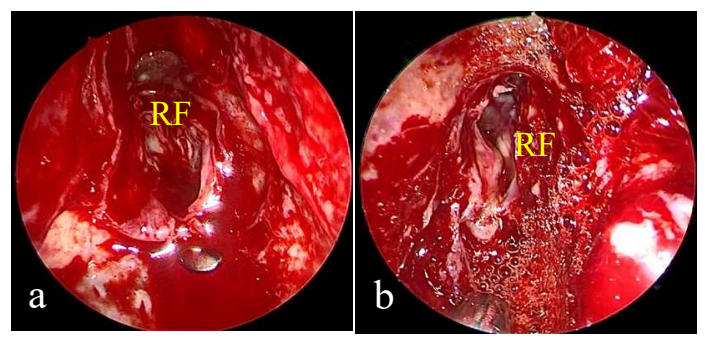

$\mathrm{RF}=$ frontalis recces

Figure 6. (a) bleeding control using warm saline irrigation. (b) bleeding was controlled provided a better surgical field.

Third case, a 20-year-old woman presented bilateral nasal congestion since two years, bilateral nasal polyps, mucopurulent nasal discharge, loss of smell, pain in both cheeks, history of regular medication two months before surgery. Nasoendoscopy revealed grade 2 polyp mass on right nostril extending to choane, and grade 3 on left nostril (Figure 7). Paranasal sinuses CT scan showed a solid mass (30-50HU) of the right and left nasal cavity, with extension to the maxillary sinus, ethmoid sinuses, sphenoidal sinuses, and right and left frontal sinuses, encountered nasopharyngeal cavity (Figure 8).

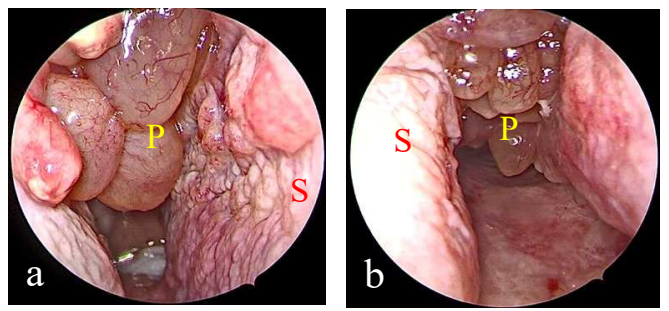

$\mathrm{P}=$ nasal polyp, $\mathrm{S}=$ nasal septum.

Figure 7. Nasoendoscopy revealed grade 2 polyp mass on right nostril extending to choane (a), and grade 3 on left nostril (b). 

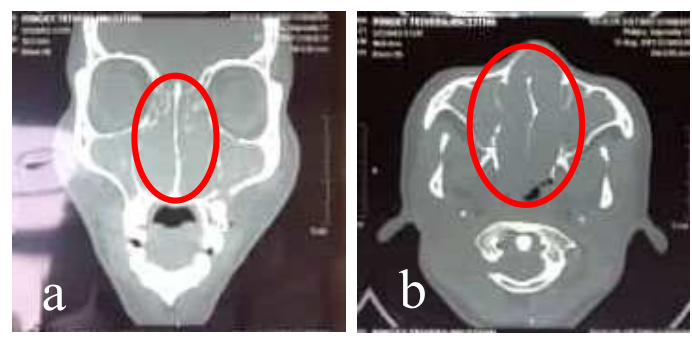

Figure 8. CT scan shows a soft tissue mass in the right and left nostril filling the nasopharyngeal cavity.

The surgery lasted for two hours without complications, blood loss was about $50 \mathrm{ml}$, Boezaart score 2 (Figure 9).

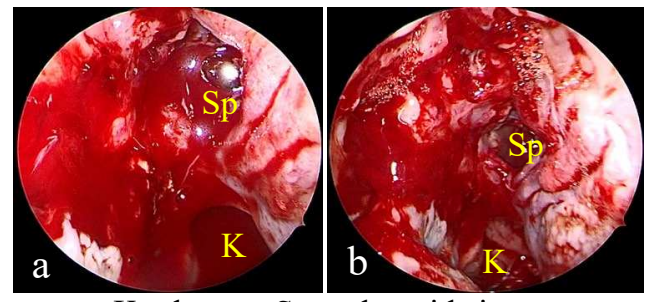

$\mathrm{K}=$ choane, $\mathrm{Sp}=$ sphenoid sinus

Figure 9. (a) bleeding control using warm saline irrigation. (b) bleeding controlled, better surgical field of view.

Fourth case, a 57-year-old male presented a bilateral nasal congestion since five months ago, thick, clear, and odorless nasal discharge, loss of smell, headache, history of medication for two months.

Nasoendoscopy revealed grade 3 polyp masses on the right and grade 3 on left nostril. CT scan showed solid masses (34HU) of the maxillary sinuses, ethmoid sinuses, spenoid sinuses, and right and left frontal sinuses, extending posteriorly to the nasopharynx (Figure 10).
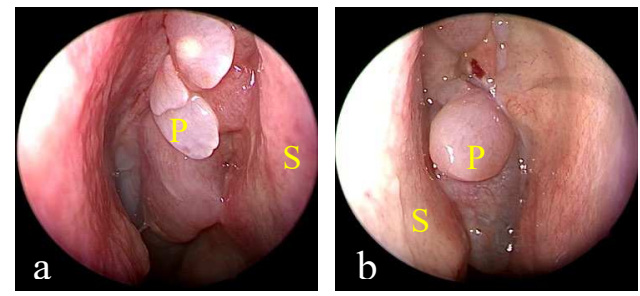

$\mathrm{P}=$ polip kavum nasi, $\mathrm{S}=$ septum nasi.

Figure 10. Nasoendoscopy revealed grade 3 polyp masses on the right (a) and grade 3 on left nostril (b). 

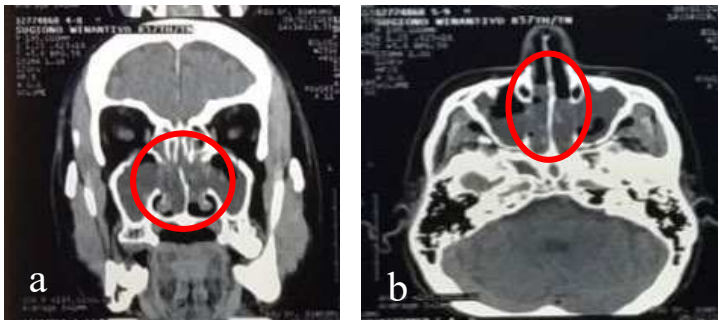

Figure 11. CT scan showed soft tissue masses in the right and left nostril extending to choane.

The surgery lasted for three hours without complications, blood loss was approximately $75 \mathrm{ml}$, Boezaart score 2 (Figure 12).

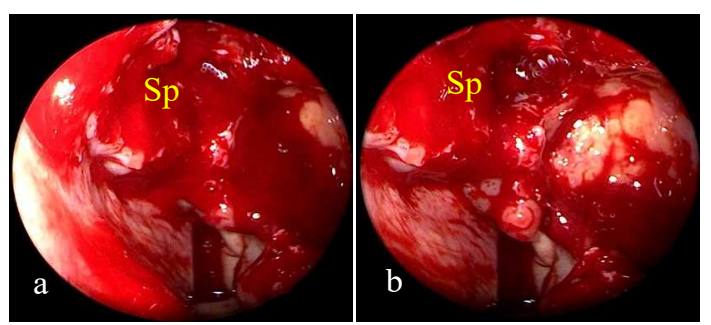

$\mathrm{Sp}=$ sphenoid sinus

Figure 12. (a) bleeding control using warm saline irrigation. (b) bleeding controlled, better surgical field of view.

A bottle of $500 \mathrm{ml}$ saline solution was put into heater to reach desired temperature up to $50^{\circ} \mathrm{C}$ and maintained in a heat-resistant container (Figure 13). Measurement of temperature using a digital thermometer with a probe immersed directly into water on the heater device. The patient in supine positioned, reverse Trendelenburg $20^{\circ} \mathrm{C}$. Desinfect the operating field with $70 \%$ alcohol. The operation field was narrowed with sterile linen and enlarged the nasal cavity by administering Oxymetazolin $0.05 \%$ and Lidocain $1 \%$. Bleeding was treated using suction, cautery, for macro blood vessels while mucosal bleeding was managed by warm saline irrigation directed to the bleeding area. Bleeding during surgery was documented by Boezaart score.

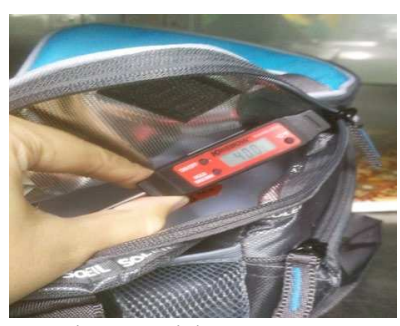

Figure 13. Storage containers with temperatures maintained at $50^{\circ} \mathrm{C}$ 


\section{Clinical Question}

How effective is warm saline irrigation for bleeding control during FESS?

\section{Method}

Literature search was carried out using electronic databases, namely PubMed 47 and Springer 39 on September 25th, 2020 with keywords ("bleeding" OR "hemorrhage" OR "intra operative blood loss" OR "hemostasis") AND ("saline" OR "isotonic saline" OR "warm" OR "warm temperature" OR "regular" OR "regular temperature" OR "room temperature") AND ("during endoscopic sinus surgery") obtained 86 journal

The literature search obtained 86 literature, it was found 3 literature that met the criteria. The literature search was carried out using inclusion criteria: 1) Patient underwent FESS with warm saline irrigation up to $50^{\circ} \mathrm{C}, 2$ ) Using room temperature saline as a comparator or control, 3) Written in English, 4) Full text available, Exclusion criteria 1) Article published more than last 10 years, (Figure 14).

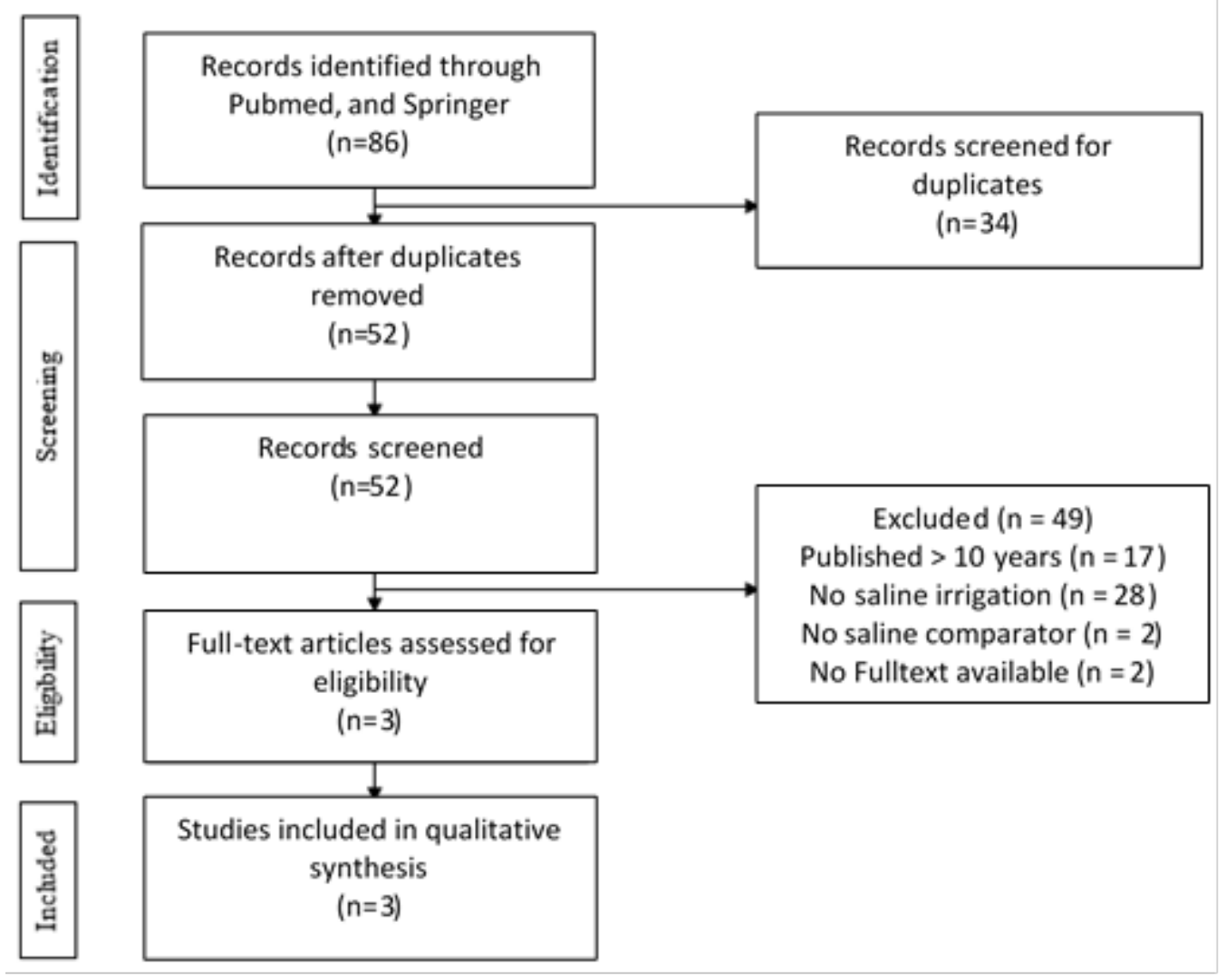

Figure 14. Search term and selection process of publication (Prisma flowchart) 


\section{Result}

Table 1. Publication obtained for Critical Appraisal

\begin{tabular}{|c|c|c|c|c|c|c|}
\hline No & Writer Journal & $\begin{array}{l}\text { Publication } \\
\text { Type }\end{array}$ & $\begin{array}{l}\text { Population/ } \\
\text { Patient }\end{array}$ & $\begin{array}{l}\text { Intervention/ } \\
\text { Index/ } \\
\text { Indicator }\end{array}$ & Comparator & Outcome \\
\hline 1. & $\begin{array}{l}\text { Gan, et al. Int Forum } \\
\text { Allergy Rhinol } \\
2014\end{array}$ & Research & $\begin{array}{l}62 \text { patient } \\
\text { underwent } \\
\text { FESS }\end{array}$ & $\begin{array}{l}\text { Warm saline } \\
\text { irrigation }\end{array}$ & $\begin{array}{l}\text { Room temp } \\
\text { irrigation }\end{array}$ & $\begin{array}{l}\text { Boezaart score is better in } \\
\text { warm temperature } \\
\text { irrigation, and significant } \\
\text { in operation duration }>2 \\
\text { hours }\end{array}$ \\
\hline 2. & $\begin{array}{l}\text { Shehata, et al. The } \\
\text { Egyptian Journal of } \\
\text { Otolaryngology } \\
2014\end{array}$ & Research & $\begin{array}{l}75 \text { patient } \\
\text { underwent } \\
\text { FESS }\end{array}$ & $\begin{array}{l}\text { Warm saline } \\
\text { irrigation }\end{array}$ & $\begin{array}{l}\text { Room temp } \\
\text { irrigation }\end{array}$ & $\begin{array}{l}\text { Average Boezaart score is } \\
\text { better in warm temperature } \\
\text { irrigation. }\end{array}$ \\
\hline 3. & $\begin{array}{l}\text { Al-Ississ, et al. } \\
\text { Journal of The Royal } \\
\text { Medical Services } \\
2016\end{array}$ & Research & $\begin{array}{l}100 \text { patient } \\
\text { underwent } \\
\text { FESS }\end{array}$ & $\begin{array}{l}\text { Warm saline } \\
\text { irrigation }\end{array}$ & $\begin{array}{l}\text { Room temp } \\
\text { irrigation }\end{array}$ & $\begin{array}{l}\text { Significant decreased of } \\
\text { blood lost in warm } \\
\text { temperature irrigation }\end{array}$ \\
\hline
\end{tabular}

\section{Discussion}

The quality of surgical field is a crucial factor during FESS. Several techniques can be applied to reduce bleeding during surgery. Warm saline irrigation with a temperature of up to $50^{\circ} \mathrm{C}$ can reduce of sinonasal mucosal blood from small vessels. ${ }^{5}$ This method was first introduced by obstetricians to control postpartum hemorrhage more than 100 years ago. In the field of rhinology this method was used by Guice and Fayette in 1878 to treat epistaxis. ${ }^{6}$ To explain its hemostatic effects, Stangerup and Thomsen conducted animal studies to investigate the histopathological changes associated with the use of warm saline irrigation. The study concluded that exposure to warm saline with temperatures between $48^{\circ} \mathrm{C}$ and $52^{\circ} \mathrm{C}$ caused mucosal edema and narrowing of the intranasal lumen. Mucosal edema creates surrounding compression of the injured blood vessels, microvascular vasodilation of the mucosa slows down blood flow thereby triggering and accelerating blood clotting. Assessment of bleeding during surgery was documented with Boezaart score. ${ }^{7}$ Another advantage of warm saline irrigation is that it keep the endoscopic lens clear. ${ }^{8,12}$

In this case, all patients were subjected to warm saline irrigation which was sprayed into the bleeding center with a temperature up to $50^{\circ} \mathrm{C}$ as management of mucosal bleeding during surgery, irrigation was carried out with $20 \mathrm{ml}$ warm saline to the mucosal bleeding center every 10 minutes or if there was an increase in the Boezaart score in the field operation assessed by the operator, besides that all patients received 
the same treatment, using the same anesthetic regimen and vasoconstrictor, the same operating instruments and without the use of microdebrider.

The blood loss was documented between 50-100 milliliters. Warm saline irrigation with a temperature of $40-42^{\circ} \mathrm{C}$ can reduce the flow of exudate from the sinonasal mucosa and reduce bleeding from small blood vessels. ${ }^{13}$ Warm saline irrigation can significantly reduce intraoperative bleeding. A study by Alississ et al., Compared warm saline irrigation at $48^{\circ} \mathrm{C}$ (group I) with room temperature saline irrigation at 20 ${ }^{\circ} \mathrm{C}$ (group II) in patients undergoing FESS and septorinoplasty procedures. The study showed that group I experienced less bleeding and smaller Boezaart score than group II. The Boezaart score is a scale assigning a numerical value from 0 to 5 , used to measure the degree of endoscopic impairment of intraoperative bleeding that occurs. ${ }^{5}$ A similar study by Gan et al. showed that the use of warm saline irrigation at $49^{\circ} \mathrm{C}$ was correlated with a reduced blood loss. Bleeding rate was 1.7 milliliters per minute whereas the use of saline at $18^{\circ} \mathrm{C}$ correlated with blood loss of 2.3 milliliters per minute. These results indicate no significant difference between the two groups. ${ }^{4}$

Research by Shehata et al., comparing the administration of local tranexamic acid (group A) with warm saline irrigation (group B) and room temperature saline irrigation (group C). The mean Boezaart scores in groups $\mathrm{A}, \mathrm{B}$ and $\mathrm{C}$ were $1.92 \pm 0.64,1.96 \pm 0.67$ and $2.64 \pm 0.7$, respectively. There were significant differences between groups $\mathrm{A}$ and $\mathrm{B}$ and groups $\mathrm{C}$, but no significant differences between groups A and B. ${ }^{6}$ Warm saline irrigation was also reported to accelerate hemostasis time and decrease the duration of surgery during FESS. The duration of FESS in this case was 120 minutes without complications. Research by AlIssiss et al. showed a significant increase in the duration of surgery in group II, namely 92.66 minutes compared to group I, 83.34 minutes $(\mathrm{P}<0.05)$. This study also mentions surgical satisfaction in terms of visibility of the surgical view related to decreased intraoperative bleeding. The proportion of surgeons who were satisfied in group I was $88 \%$ compared to group II at 32\%. ${ }^{5}$ Shehata et al. Study reported a duration of surgery of $75.92 \pm 7.64$ minutes in group A, $74.22 \pm 7.54$ minutes in group B and 98.54 minutes in group C (P $=0.0002$ ). These data show a significant difference between groups A and B and group C. ${ }^{6}$

Parameters used in this case report included the length of surgery which ranged from one and a half to three hours, the amount of bleeding ranged from fifty to one hundred milli liters. The assessment of comfort in the operating field of view can be directly proportional to the level of bleeding during the surgery process, the less bleeding, the better the visual field, the Boezaart score in all four patients reported was 2 . Complications in all patients during surgery were not found.

The use of warm saline as control of mucosal bleeding in four patients who underwent a functional endoscopic sinus surgery of the whole sinus or full-house FESS showed satisfactory results. Further studies 
are recommended to detect the optimum time needed to achieve the hemostatic effect after the application of warm saline and larger amount of patient population to further effectiveness of these agents.

\section{Acknowledgement}

The authors would like to thank Faculty of Medicine, Universitas Airlangga, Dr. Soetomo General Hospital, Surabaya, and Department of Otorhinolaryngology Head and Neck Surgery for supporting this study.

\section{Source of Funding}

Self-Funded

\section{Conflict of Interest}

The authors declare there are no conflicts of interest
Abbreviations :
FESS : Functional Endoscopic Sinus Surgery
CRS : Chronic Rhinosinusitis
AFRS : Allergic Fungal Rhinosinusitis
CT scan : Computed Tomography scan
HU : Houndsfield Unit

\section{REFERENCES}

1. Thongrong C, Kasemsiri P, Carrau RL, Bergese SD. Control of bleeding in endoscopic skull base surgery: current concepts to improve Hemostasis. Hindawi Publishing Corp 2013; 1:1-11.

2. Tirelli G, Lucangelo U, Sartori G, Da Mosto MC, Boscolo-Rizzo P, Bussani R, et al. Topical steroids in rhinosinusitis and intraoperative bleeding: more harm than good?. Ear, Nose Throat Journal 2019; $1: 1-7$.

3. Pant H. Hemostasis in endoscopic sinus surgery. Elsevier Inc 2016; 49(3):655-76.

4. Gan EC, Alsaleh S, Manji J, Habib AR, Amanian A, Javer AR. Hemostatic effect of hot saline irrigation during functional endoscopic sinus surgery: a randomized controlled trial. Int Forum Allergy Rhinol 2014;4(11):877-84.

5. Al-Ississ A, Al-Khaldi H, Maayah A, Kilani NK. Effect of warm saline on bleeding during sinus and septum surgery. Journal of The Royal Medical Services 2016; 23:17-21. 
6. Shehata A, Ibrahim MS, El-Fattah MHA. Topical tranexamic acid versus hot saline for field quality during endoscopic sinus surgery. The Egyptian Journal of Otolaryngology 2014; 30:327-31.

7. Alsaleh S, Manji J, Javer A. Optimization of the surgical field in endoscopic sinus surgery: an evidence-based approach. Curr Allergy Asthma Rep 2019; 19(1):1-10.

8. Özmen S, Özmen OA. Hot saline irrigation for control of intraoperative bleeding in adenoidectomy: A randomized controlled trial. Otolaryngology - Head and Neck Surgery 2010; 142(6):893-7.

9. Snyderman CH, Pant H, Carrau RL, Prevedello D, Gardner P, Kassam AB. What are the limits of endoscopic sinus surgery? the expanded endonasal approach to the skull base. Keio J Medical Society 2009;58(3):152-60. 